\title{
EVALUATION OF DIFFERENT COLOURED STICKY TRAPS FOR MONITORING KELLY'S CITRUS THRIPS (PEZOTHRIPS KELLYANUS)
}

\author{
K.J. FROUD \\ HortResearch, Private Bag 92169, Auckland
}

Kelly's Citrus thrips (KCT), (Pezothrips kellyanus) is currently the most important pest affecting citrus production in New Zealand. It causes severe rind damage and reduces market value of most types of citrus. In developing a monitoring system for KCT, three different coloured sticky traps (white, yellow, and blue) were compared for attractiveness to KCT. Traps were placed within the canopy of Meyer lemons in Kerikeri and South Auckland. A randomised block design with five replicates was used over a period of 28 days and traps were changed and re-randomised after 14 days. The numbers of thrips on a $10 \mathrm{~cm}^{2}$ section on both sides of each trap were counted. In South Auckland, only low numbers of KCT were caught and there were no significant differences in numbers between traps. Higher numbers of KCT were found at the Kerikeri site. White traps caught significantly more thrips than yellow or blue traps $(\mathrm{P}<0.01)$. White traps caught a mean of 73.3 ( $\pm 12.5 \mathrm{SE}) \mathrm{KCT}$ per fortnight compared to a mean of $5.1( \pm 0.9 \mathrm{SE})$ and $8.4( \pm 2.4)$ thrips per fortnight for yellow and blue traps respectively.

\section{HOST FINDING BEHAVIOUR OF APHELINUS MALI, A PARASITE OF THE WOOLLY APPLE APHID}

\author{
M. SANDANAYAKA AND M.O. HARRIS
}

The Horticulture and Food Research Institute of New Zealand Ltd., Private Bag 92169, Auckland, New Zealand

\begin{abstract}
Aphelinus mali (Hymenoptera: Aphelinidae) is a major parasitoid of the woolly apple aphid, Erisoma lanigerum (Hemiptera: Pemphigidae). The host finding behaviour of A. mali contributes to its effectiveness as a biological control agent. We examined the host finding behaviour of $A$. mali using a Y-tube olfactometer. One to two day old naive and experienced parasites were tested separately. Prior to the test, experienced parasites had been allowed to forage for 30 minutes on woolly apple aphid colonies. In the first test, when parasites were given a choice of odours of an apple twig or clean air, both naive and experienced parasites oriented to the odours of the apple twig. In the second test, when given a choice of uninfested apple twigs or wooly apple aphid infested apple twigs, the experienced females were more likely to orient to odours from the infested apple twig. Naive females were more likely to orient to odours from uninfested twigs. These results indicate that $A$. mali uses odours to find the habitat of the woolly apple aphid, and that these odour mediated responses may be modified after the parasitoid has experienced its host.
\end{abstract}

